\title{
Entre políticas públicas e a soberania popular: estado e democracia participativa na América do Sul
}

Cláudio Azevedo'

Aruã Silva de Lima²

\section{Resumo}

Um dos aspectos centrais para iniciar qualquer indagação acerca das conquistas democráticas em sociedades que conviveram durante o século XX com regimes autocráticos é a questão da liberdade. Nela imbricam-se outras duas: ação política e capacidade de associação. É evidente que, em se tratando apenas da esfera política, a ideia central do presente argumento é que os recentes movimentos de ampliação das formas de manifestação de uma democracia participativa, por meio de referendos, principalmente na América do Sul, são também frutos de uma experiência interrompida entre os anos 60 e 80 do século XX. Por outro lado, também se pretende indagar sobre o modo como o Estado ${ }^{3}$ tem tutelado essas instâncias de exercício de poder popular das mais variadas formas; dentre elas, a amputação das bandeiras universais e emancipatórias, traduzindo-se como uma gritante diferença entre os movimentos populares das décadas de 60 a 80 e os mais recentes que têm levado à formação de governos com ampla mobilização popular.

\footnotetext{
${ }^{1}$ Mestrando em Direito Público pela Universidade Federal da Bahia; Pós-graduando em Direito Marítimo e Portuário pela Universidade Católica de Santos; professor de cursos de extensão e pós-graduação em Teoria Geral do Direito, Direito Constitucional e Internacional em Salvador, Santos, São Paulo e Caracas - Venezuela; e advogado (sócio-fundador) do Ferreira Lima Krull Ventin \& Azevêdo Advocacia e Consultoria. Email: claudioazevedo@flkva.com.br

${ }^{2}$ Mestrando em História pela Universidade Estadual de Feira de Santana. Email: arualima@ gmail.com.

${ }^{3} \mathrm{O}$ conceito de Estado permite uma longa digressão. Exatamente por isso, pretende-se restringir a utilização do conceito à sua forma gramsciana de Estado ampliado onde ele é produto das lutas sociais e existe em prol de uma classe dominante em dada sociedade. Sua atuação varia entre a coerção e o convencimento de modo que ambas as ações fazem parte do estágio estrutural das lutas de classes.
} 


\section{Democracia, esquerda e participação popular: liberdade vigiada}

Os anos de luta contra o imperialismo e pela libertação nacional circunscrevem-se, de modo amplo, na segunda metade do século XX. O discurso em torno da libertação dos povos - portanto, o tema da liberdade - misturou-se às bandeiras de grupos subalternos em todo o globo. No Brasil não seria diferente pelo simples fato de o país se encontrar imerso na engrenagem complexa do mundo pós-45. ${ }^{4}$ Comunistas e trabalhistas, como correntes políticas, apoiavam o governo João Goulart e travavam, desde meados da década de 1950, árdua batalha pela defesa da ordem constitucional e pela manutenção do Estado de Direito. Setores legalistas das Forças Armadas Brasileiras também o fizeram, pelo menos em duas ocasiões - 1958 e 1961. Tratava-se de um momento de grande efervescência popular, haja vista a crescente organização de trabalhadores urbanos e de camponeses que avançavam cada vez mais numa pauta reivindicativa em direção ao tensionamento da democracia histórica. ${ }^{5}$ Não cabe discorrer sobre as motivações e realizar um balanço acerca das forças políticas que compunham o cenário conflituoso. A grande questão é: quando, num momento de agudização de conflitos, grupos subalternos unificam-se e criam mecanismos próprios nas tomadas de decisões, construindo uma agenda própria de exercício de cidadania e, a partir disso, de crítica ao status quo, tem-se um processo democrático? Ou, um processo democrático necessariamente perpassa pela partilha do poder decisório do Estado?

A questão, talvez, fosse mais bem posta se a ideia de democracia se fizesse presente não tanto como um método de exercício de poder e sim, como instituição sociopolítica disputada na dinâmica do cotidiano de cada sociedade. A caracterização, portanto, da democracia estaria posta sob disputa entre sujeitos sociais. Desse modo, as análises da complexidade dos processos que têm como pano de fundo a questão da liberdade e emancipação do homem. Compreender, destarte, o exercício da democracia no Brasil e, principalmente, os sujeitos que propugnaram agendas democráticas significa compreender os papéis de classe desempenhados pelos protagonistas da história recente no Brasil e, analogamente, dos demais países sul-americanos.

\footnotetext{
${ }^{4}$ Aqui se faz referência, sobretudo, aos anos de Guerra Fria, à polarização ideológica e, principalmente, à reestruturação produtiva imposta aos trabalhadores.

${ }^{5}$ Refere-se à experiência concreta de democracia. Os sujeitos que vivenciaram os anos pré64 concebiam viver numa democracia ainda que lhe imputasse críticas.
} 


\section{As concepções de soberania popular e esfera pública: fundamentos da participação popular na América do Sul}

A perpetuação de um regime de democracias representativas acabou por gerar um verdadeiro engodo sociopolítico: as "meias-democracias" ou as "semirrepresentatividades". Essas formas de governo perpetuaram a participação indireta do cidadão na condução dos assuntos públicos - por meio das eleições; participação esta, contudo, que se revelou totalmente atrofiada, pois os cidadãos possuem poucos meios de controle de seus representantes e tampouco possuem maneiras de exigir o vínculo dele aos compromissos firmados no momento eleitoral.

Pretende-se, então, indagar qual o impacto dessa perpetuação de prática de poder na (des)valorização da democracia participativa, fundada na necessidade de conceder àquele poder dado aos representantes democráticos mais legitimidade, isto é, de aproximar mais os cidadãos nas tomadas de decisões; de sair do estado em que era participado - comunicado - dos rumos do país, para um outro cenário em que ele deixa a posição de coadjuvante para também participar daquelas tomadas de decisões. Na democracia participativa, os cidadãos passam a assumir de maneira efetiva a condução da coisa pública, legitimando, constantemente, o poder que foi dado àqueles representantes eleitos. Logo, isso quer dizer que esse regime não nega que existam representantes, mas sim ressalta que o direito que determinado indivíduo assume ao ser eleito legalmente tem limites; limites estes que residem na soberania popular, isto é, na legitimidade, sendo renovada constantemente pelos cidadãos. Deve-se, assim, observar os mecanismos de organização comunitária, bem como a existência (e o tipo) de políticas públicas que interfiram na conscientização populacional e na ampliação do direito à cidadania.

Além desse reflexo interessante, observamos a mutação que sofreu a concepção de soberania popular - principalmente nos regimes de Direito Democrático sul-americano alicerçado nos direitos fundamentais. É importante notar que os Estados de nosso continente nasceram a partir uma raiz ibérica, fundada no interesse privado e no autoritarismo das relações sociais, que sempre foram/ são fundadas em um verticalismo e em uma hierarquia social. Não é por acaso que notamos, a despeito de outros países de situação cultural distinta, o grande protagonismo conferido ao poder executivo na América do Sul. 
Contudo, como já foram pontuadas acima, as mudanças nas formas de mobilização social, iniciadas nas décadas de 60 e 70 - que são abortadas por um período ditatorial -, retornam ao cenário político sul-americano no século XXI. São essas mudanças que vão provocar a "mutação" da concepção de soberania popular. Assim, aquela sociedade, alicerçada principalmente em interesses privados, por meio de ações coletivas, exigirá uma maior participação na tomada de decisões estatais, o que demanda o surgimento do fenômeno da transparência estatal (publicização), refletindo a ampliação do domínio público, antes fechado a interesses coletivos. Então, a legitimação da soberania popular, em um processo contínuo de concretização passará a fundar-se na esfera das relações sociais e não mais apenas na esfera institucional do Estado.

Dessa forma, a concepção de soberania popular ganhará novo significado, devido à mudança ocorrida no espaço público. Este, por sua vez, passará a se basear, não mais naqueles interesses privados, mas sim, fundamentalmente, naquela soberania popular e na publicização da informação. A ampliação da esfera pública cria, assim, um espaço de interação entre os seres humanos, o que permite a formação de grupos e movimentos sociais que passam a apresentar demandas e a reivindicar câmbios nessa esfera. Essa apresentação de demandas e esses conjuntos de reivindicações foram alicerçados justamente pela publicização da informação que, da mesma forma, ampliou o domínio público ao possibilitar a politização de novas questões antes não relevantes para a sociedade. ${ }^{6}$ As organizações não-governamentais de proteção ao meio ambiente são um bom exemplo da realidade vivida pela esfera pública atualmente, pois apresentam frequentemente demandas ao Estado, que são frutos de um processo de busca por informação e debate de argumentos dentro desses espaços comuns.

Assim, perceba-se, o espaço público não pode ser encarado como instituição - pois não regula competências -, nem como sistema - visto que possui horizontes abertos e deslocáveis -, e tampouco como organização - já que não regula nada. A esfera pública, de acordo com o que foi dito no parágrafo anterior, parece ser uma rede de comunicação entre aqueles atores sociais, em que são intercambiados diversos conteúdos, posições e opiniões. Logo, será essa rede que "selecionará" os

\footnotetext{
${ }^{6}$ HABERMAS, Jürgen. The structural transformation of the public sphere: an inquiry into a category of bourgeois society. Cambridge: MIT Press and Polity Press, 1989.
} 
melhores argumentos que serão solidificados como opinião pública. ${ }^{7}$ Observe-se, então, que a concepção de esfera pública como a reunião de interesses meramente privados, sofre uma drástica mudança, visto que os titulares desse espaço passam a ser os cidadãos do Estado. Dessa forma, os conteúdos, posições e opiniões elaboradas na esfera privada servirão, agora, de base para que a esfera pública retire seus estímulos comunicacionais. Desse modo, a esfera pública vai ser uma rede em fronteiras que será intermediária entre os setores privados, de um lado, e o sistema político, de outro. Nessa ligação, reside a participação popular.

Logo, pode-se concluir que essa nova concepção de soberania popular vai ser baseada na participação social, no exercício diário de busca de informações e nos conhecimentos para encontrar argumentos que melhor possam influenciar a tomada de decisões dos representantes sociais no âmbito Executivo, Legislativo e Judiciário. Assim, a própria democracia sofrerá um câmbio de rumo, caminhando em direção a uma inclusão do instituto da participação popular, visto que a sociedade civil ganha, com essa mudança na concepção da soberania popular, um novo núcleo de composição com movimentos sociais, bem como organizações e associações civis. Tal núcleo passa a ser, então, o responsável por captar a realidade dos problemas sociais que repercutem na esfera privada, melhorando seus "argumentos" e "conteúdos", transmitindo-os ao espaço público. ${ }^{8}$ Nessa função, encontra-se um dos papéis mais relevantes da sociedade civil para o regime estatal democrático.

Contudo, obviamente, esse conteúdo de transmissão da esfera privada para a pública (influência) vai concorrer com outros conteúdos, argumentos e opiniões dentro da grande rede de comunicação que é a esfera pública. Tais inputs fornecidos pela sociedade civil sofrerão uma nova ponderação - agora já dentro da esfera pública - com os conteúdos (influências) fornecidos pelos meios de comunicação e pelas organizações políticas. Não é necessário muito esforço intelectual para perceber que a influência da sociedade civil será menor dentro dessa rede de comunicações (espaço público), se comparada ao poder de influenciar dos dois outros atores comunicacionais. Será esta a tese que norteará a necessidade de uma maior

\footnotetext{
${ }^{7}$ HABERMAS, Jürgen. Direito e democracia: entre facticidade e validade II. Tradução: Flávio Beno Siebeneichler. Rio de Janeiro: Tempo Brasileiro, 1997.

${ }^{8}$ Ibidem.
} 
participação popular na elaboração e no controle de políticas públicas, demanda essa que se impregnará de legitimidade com o alicerce da soberania popular.

\section{Políticas públicas}

Todos esses elementos propiciam um novo panorama de políticas públicas nos países da América do Sul, qual seja, a elaboração, no âmbito dos três poderes, de uma série harmônica de ações coletivas que visem garantir os direitos fundamentais, sobretudo em nosso estudo, e a participação do cidadão; ações estas que devem deixar o sentimento subjetivo de desejo social, para consolidarem-se como um verdadeiro compromisso socioestatal. Como se percebe, essas políticas públicas - policies - seriam verdadeiros outputs daqueles inputs inseridos na esfera pública pelos atores sociais. Logo, uma política pública será composta por diversas decisões e não-decisões ${ }^{9}$ políticas e será efetivada por diversas ações que busquem implementar tais decisões, que serão formadas em torno de interesses ou questões (issues). Aqui, reside a afirmação de que a esfera pública é uma rede de comunicações baseada na argumentação. O problema para o Estado de Direito Democrático dar-se-á quando a sociedade civil for sufocada por outros atores do espaço público, aniquilando, assim, a participação popular na construção das ações e decisões políticas.

Contudo, nitidamente, existem diversos obstáculos para a concretização da participação do cidadão e a efetivação de seus direitos fundamentais mediante políticas públicas orientadas à democracia participativa. Um primeiro obstáculo, o estrutural - primeiro óbice identificado nas investigações sobre o tema -, impedirá que a implementação das políticas públicas seja baseada também nas influências da sociedade civil e que possa por ela ser acompanhada e regulada. Em outras palavras, o obstáculo estrutural mostra quais barreiras impedem que a sociedade civil ajude, influencie e fiscalize o processo de implementação, fazendo que uma política saia do papel e funcione efetiva e eficientemente.

\footnotetext{
${ }^{9}$ A não-decisão não significa falta de decisão, mas sim significa que certos conteúdos, argumentos ou opiniões encontram entraves para sua transformação em elemento da agenda governamental, devido ao conflito de interesses ou de valores, por exemplo.
} 
Como obstáculos estruturais, podem ser inicialmente citados dois fatores: (1) a ineficiência das ferramentas ou mecanismos já existentes que buscam garantir a participação do cidadão como fonte da legitimidade estatal e (2) a manutenção da tutela estatal na condução dos organismos na tomada de decisão.

O primeiro obstáculo estrutural vai refletir um cenário de falta de comunicação horizontal entre os espaços de participação popular - como os conselhos de políticas e as conferências. Isto é, falta a tais associações ou instâncias de formação de opinião e argumentos um diálogo entre si, pois o que se observa é que cada conselho pesquisa, decide e age de maneira isolada, sem aproveitar os pontos de vista gerados por outras instâncias de participação popular, sejam elas conferências, ONG’s ou associações comunitárias. Sem dúvidas, o papel dos conselhos da República, por exemplo, é limitado e muitas vezes pouco eficiente na capacidade de influir no processo decisório e de fiscalização de políticas públicas, visto que a participação do cidadão nesses conselhos configura-se por meio de consultas isoladas, perpetuando a fragmentação existente no âmbito das políticas públicas.

Por outro lado, percebe-se que o vetor Estado-Sociedade Civil poderia ter um sentido duplo ou até mesmo inverter-se pontualmente como forma de ampliar a participação popular na efetivação das políticas públicas. O Estado segue mantendo sob sua tutela o papel de decidir sobre as políticas públicas, ainda que a temática a ser decidida seja extremamente restrita a apenas uma comunidade pontual. Na Venezuela, questões de interesse pontual de determinada comunidade são decididas, em alguns casos, pela própria comunidade, como no caso das comunas, que são núcleos básicos da sociedade que reúnem pessoas que vivem juntas em uma mesma rua ou em um mesmo bairro. Assim, nota-se uma descentralização do poder decisório do Estado, em questões pontuais, que dá a um grupo de pessoas, cujo denominador comum seja o fato de compartilhar o mesmo espaço de vida, as condições de tomar consciência de seus interesses comuns e, com isso, ter a possibilidade de defendê-los. Tal giro do vetor decisório seria a perpetuação da ideia de espaço público como rede complexa de comunicação que liga os interesses privados ao sistema político, visto que a relação entre esses seres individuais e co- 
letivos permite uma fusão de horizontes ${ }^{10}$ que vai pôr em comum visões de mundo distintas, mas que devem ser pensadas para aquela comunidade e não no âmbito meramente privado, de modo a poder transformar positivamente a realidade.

\subsection{A experiência brasileira: iniciativas para a superação dos obstáculos estruturais e reflexos no campo do direito e da ciência política}

Como modo de neutralizar ou de tentar solucionar tais obstáculos à concretização da participação do cidadão nas sociedades sul-americanas, observamos algumas iniciativas que sejam legislativas, jurídicas e executivas e que refletem o câmbio operado na esfera pública e a "mutação" da concepção de soberania popular, com a ampliação do domínio público a partir da maior transparência dos atos estatais.

Foi no final da primeira década do século XXI, com o advento das novas Constituições democráticas no pós-ditadura - que estão começando a ser efetivadas de maneira mais incisiva agora -, que alguns instrumentos de democracia participativa passaram após período de interrupção nas décadas de 60 e 70 - a ganhar, novamente, relevância no cenário democrático atual da América do Sul: ${ }^{11}$ as audiências e consultas públicas, conselhos gestores e consultivos, referendos e plebiscitos, bem como a consagração da iniciativa popular para propositura de lei. Tais Constituições abarcaram no rol de direitos fundamentais, por exemplo, a liberdade de expressão e de reunião, além do direito de se associar e se reunir livremente, como mostra dessa mudança, no espaço público, já que tais direitos fundamentais permitirão que associações livres possam interferir na opinião pública. Todas essas formas de expressão da democracia participativa voltaram a ser usadas na América do Sul como forma de legitimar mudanças - como sucedido recentemente na Bolívia. Podemos ainda citar exemplos de participação popular na esfera pública, como o orçamento participativo e a iniciativa popular no Brasil.

\footnotetext{
${ }^{10}$ Expressão cunhada por Hans-Georg Gadamer. No caso em estudo, tal conceito pode ser aplicado como a capacidade que tem o ser humano de tomar consciência, compreender e interpretar a realidade em que vive, podendo criar possibilidades de mudanças sociais. GADAMER, Hans-Georg. Verdade e método. Petrópolis: Vozes, 1997.

${ }^{11}$ Outro ponto interessante a que se propõe este estudo é identificar em que momento democrático a América do Sul se encontra atualmente. Nós tentamos assinalar um momento como fase pós-neoliberal, em alusão ao retorno, em alguns países mais e em outros menos, de uma nova espécie de intervencionismo estatal. Contudo, como fora dito acima, tal tema ainda será objeto de estudo mais acurado para que possa ser devidamente comentado.
} 
Entre as novas iniciativas legislativas, podemos citar, no âmbito do Senado Federal brasileiro - apesar de estas propostas estarem fora do foco de debates legislativos atuais - o PLS 215/1999 que dispõe sobre a participação popular e o controle social dos atos de gestão do poder público e disciplina o acesso dos cidadãos e da sociedade civil organizada à informações relativas às finanças públicas. Além disso, também trata do tema o PLS 596/1999 que dispõe sobre o controle social dos atos de gestão da Administração Pública empreendidos ou descentralizados no âmbito estadual ou municipal, mediante programas federais, e assegura o livre acesso dos cidadãos às informações relativas às finanças públicas. Por outro lado, o PL 110/2003 inclui entidades da sociedade civil como usuários dos sistemas de consulta, fiscalização e acompanhamento orçamentário, administrativo, fiscal e monetário da Administração Pública, direta e indireta Perceba-se que todos esses projetos de lei buscam fundamentalmente ampliar a esfera pública, no sentido de permitir uma maior transparência dos atos estatais, e assim possibilitar uma maior participação popular - já que ela se fundamenta na possibilidade de informação e comunicação.

Ademais, podemos citar o Projeto de Lei apresentado pelo Conselho Federal da Ordem dos Advogados do Brasil (OAB), a partir de proposta de Fábio Konder Comparato e que tem o objetivo de regulamentar o artigo 14 da Constituição Federal. Se tal Projeto de Lei for aprovado, a) seria possível a convocação de plebiscito e referendo a partir de iniciativa popular, seguindo os mesmos parâmetros da iniciativa popular legislativa; b) haveria hipóteses em que o plebiscito deveria ser necessariamente realizado; c) seria dado tratamento especial à iniciativa popular legislativa, facilitando as informações a serem apresentadas pela população. Outra iniciativa legislativa seriam as propostas de Emenda Constitucional (PEC) 463/2005 - que possibilitam a autoconvocação popular para a realização de um Plebiscito - 478/2005 - para decidir sobre antecipação das eleições - e outro - 498/2006 - que submete à opinião pública proposições não apreciadas pelo Congresso Nacional no prazo de duas legislaturas.

Tais Projetos de Lei visam somar os esforços dos dispositivos legais que incentivam a participação popular já presentes na Constituição Federal de 1988, tais como: inciso VII, parágrafo único, do art. 194, que trata da seguridade social; inciso II, do art. 204, que cuida da temática da Assistência Social; bem como o parágrafo $1^{\circ}$, do art. 227, que regula os deveres da família, da sociedade e do Estado perante à 
criança e aos adolescentes. Assim, busca-se efetivar os direitos fundamentais da livre associação, bem como da soberania popular.

No âmbito jurídico, um importante reflexo dessa tendência de participação do cidadão na coisa pública pode ser apontado pelo uso da figura do amigo da corte (amicus curae) que possibilita, de forma direta, a participação de determinadas comunidades no momento argumentativo que influencia a decisão do magistrado, abrindo a interpretação de problemas presentes na demanda não apenas para autor, réu e juiz, mas abarcando também as comunidades interessadas no caso. Notadamente, tal instrumento de participação popular reputará mais legitimidade ao discurso jurídico do Judiciário, ampliando, assim, o domínio público participado ao cidadão e o círculo de interpretação dessas normas jurídicas. Ajuda-se a construir assim uma sociedade aberta de intérpretes. ${ }^{12}$

Iniciativas como a implantação no Brasil do projeto pioneiro no mundo de "processo eletrônico", ${ }^{13}$ a efetivação do direito de ação do cidadão, dando a ele a possibilidade de demandar ações populares, ${ }^{14}$ bem como a realização de constantes consultas populares pelo Ministério Público para legitimar demandas sociais, que visem resguardar interesses difusos e coletivos, são exemplos claros de como se busca ampliar a participação popular nos processos decisórios, ainda que se mantenha - como constatamos no segundo obstáculo estrutural - a tutela da decisão nas mãos do Estado. Todas essas iniciativas colaboram para uma efetivação, não apenas da participação popular, mas também da publicização das informações relevantes para os cidadãos, bem como do direito fundamental ao acesso à justiça.

Por fim, podemos ainda sinalizar algumas iniciativas do Poder Executivo para a ampliação da participação popular, seja no opinativo - como sucede na Constituição de Conselhos Populares -, seja no controle e fiscalização das ações

${ }^{12}$ HÄBERLE, Peter. Hermenêutica constitucional: a sociedade aberta dos intérpretes da Constituição: contribuição para a interpretação pluralista e "procedimental" da Constituição. Porto Alegre: SAFE, 2002.

13 "Processo eletrônico" é expressão que significa a informatização do processo judicial, dada pela Lei n. 11.419, de 19 de dezembro de 2006 que permite, entre outras regulamentações o uso de meio eletrônico na tramitação de processos judiciais, comunicação de atos e transmissão de peças processuais.

${ }^{14}$ Inciso LXXIII, do art. 5 da Constituição Federal de 1988. 
e aplicação orçamentária - algumas prefeituras e governos divulgam por meio de suas páginas web a folha de gastos e investimentos, para o acompanhamento da população.

Tímidos ou arrojados, todos esses reflexos são, sem dúvidas, mostras da necessidade de uma investigação pormenorizada do que parece se constituir como uma nova tendência de concretização e efetivação dos direitos humanos no hemisfério sul-americano. Assim, se a democracia participativa vai possibilitar conferir ao Estado de Direito um adjetivo como o "Democrático", fundado na soberania popular e imerso em redes complexas de comunicação, podemos falar de um direito fundamental à participação popular. Por outro lado, como todo Estado de Direito traz em seu âmago a relação necessária entre direitos e deveres, podemos falar, ao mesmo tempo, de um dever de participação popular.

Entretanto, apesar de todas essas iniciativas, falta a possibilidade ventilada anteriormente de inversão do vetor Estado-Sociedade Civil na tomada de decisões. Esse, sem dúvidas, é um interessante caminho para estudo e reflexão das comunidades sul-americanas em geral, pois busca dar ainda mais efetividade à participação popular, além de buscar ampliar significativamente a influência dos setores de base na construção do espaço público.

\section{Considerações Finais}

Conforme explicitado, a presente proposta de investigação tem por objetivo indagar-se acerca da invenção da democracia na América do Sul, observando a história recente desses povos, impõe-se um olhar metodológico que privilegie uma interlocução permanente entre algumas disciplinas do conhecimento humano. Como constructos culturais, porque históricos, a produção historiográfica e o direito situam-se no mesmo campo como subprodutos dos povos. Desse modo, há que se estabelecer metodologicamente o objeto dessa investigação já que as formulações acerca da democracia - ou qualquer outra ideia - estão submetidas às mais diversas práticas sociais (e exatamente por isso a democracia não pode, na América do Sul, ser igual à sua similar europeia). Examinar as ideias significa analisar as formações sociais, ou, em última instância, percorrer os caminhos trilhados pelas diferentes propostas científicas das ciências humanas. 
Tratando-se de uma proposta de estudo e de pesquisa monumental, além de possuir ambições prescritivas, a presente investigação circunscreverá, do ponto de vista da pesquisa, uma análise dos mecanismos jurídicos elaborados nos últimos anos de modo a investigar a possível aparição de ferramentas de participação popular.

Um dos temas essenciais que, embora pontuado no decorrer do texto, merece uma atenção metodológica específica é a ideia de liberdade tal qual engendrada nas sociedades sul-americanas. Sua acepção jurídica é só mais uma, e não necessariamente apresenta-se como hegemônica no trato social. Tal atenção se coloca como essencial para a presente investigação, especialmente porque a disputa em torno das diversas "liberdades" implica em diferentes noções de associação de trabalhadores, comunidades e liberdade de imprensa, mostrando qual panorama de participação popular teremos na sociedade atual.

\section{Between public policies and popular sovereignty: The State and participative democracy in South America}

\section{Abstract}

The current analysis about South American democracy usually focus normative aspects rather than concrete cases based actual on latin - american's experience. The challenge proposed here is to evaluate the historical construction of democracy in recent Brazilian history making parallel remarks with neighboring countries' experiences.

Keywords: Public policies. Popular sovereignty. Participative democracy.

\section{Referências}

ABENSOUR, Miguel. A democracia contra o Estado: Marx e o momento maquiaveliano. Belo Horizonte: UFMG, 1998.

AQUINO, Maria Aparecida. Censura, imprensa, Estado autoritário: o exercício cotidiano da dominação e da resistência: O Estado de São Paulo e Movimento (1968-1978). Bauru: EDUSC, 1999. 
CARVALHO, José Murilo. A formação das almas: o imaginário da República no Brasil. São Paulo: Companhia das Letras, 1990.

DELLASOPPA, Emilio. Ao inimigo, nem justiça: violência política na Argentina (19431983). São Paulo: HUCITEC, 1998.

ELEY, Geoff. Forjando a democracia: a história da esquerda na Europa, 1850-2000. São Paulo: Fundação Perseu Abramo, 2005.

GADAMER, Hans-Georg. Verdade e método. Petrópolis: Vozes, 1997.

HABERMAS, Jürgen. Direito e democracia: entre facticidade e validade II. Tradução: Flávio Beno Siebeneichler. Rio de Janeiro: Tempo Brasileiro, 1997.

The structural transformation of the public sphere: an inquiry into a category of bourgeois society. Cambridge: MIT Press and Polity Press, 1989.

HÄBERLE, Peter. Hermenêutica constitucional: a sociedade aberta dos intérpretes da Constituição: contribuição para a interpretação pluralista e "procedimental" da Constituição. Porto Alegre: SAFE, 2002. 
